\title{
Optimized Bioprocess for the Formulation of Liquid Microbial Inoculants for Forage Cowpea and Insight of Plant-microbe Interaction by SEM
}

\author{
S. Ramya ${ }^{1}$, Gulab Pandove ${ }^{2}$, Anu Kalia ${ }^{3}$
}

10.18805/LR-4741

\begin{abstract}
Background: In the present investigation bioprocess for the formulation of liquid microbial inoculants with escalated shelf stability for forage cowpea has been standardized. The forage cowpea can make a relevant contribution towards livestock fodder and supply nitrogen to the soil.

Methods: In the present study viability of Burkholderia seminalis, Burkholderia sp. and Bradyrhizobium sp. was evaluated for one month in a basal medium amended with different concentration of polyvinyl alcohol (PVA) $(0.5 \%, 1 \%, 2 \%$ and $3 \%)$, trehalose (5 mM, $10 \mathrm{mM}, 15 \mathrm{mM}$ and $20 \mathrm{mM})$, polyethylene glycol (PEG) $(0.5 \%, 1 \%, 2 \%$ and $3 \%)$ and glycerol (1\%, 3\%, 5\% and $7 \%)$.

Result: At $30^{\text {th }}$ day, maximum growth and survival was observed in the basal medium amended with $5 \mathrm{mM}$ trehalose for all the three test cultures. Further, Liquid microbial inoculants of Burkholderia seminalis, Burkholderia sp. and Bradyrhizobium sp. were prepared using trehalose $(5 \mathrm{mM})$ in basal medium and viability retention was studied up to 180 days of storage and compared to charcoal carrier based formulations at room temperature. Furthermore, Scanning electron microscopy provided insight of root colonization of forage cowpea by liquid microbial inoculants under gnotobiotic conditions, maximum root surface colonization was observed by liquid microbial inoculants of Burkholderia seminalis followed by Burkholderia sp. and Bradyrhizobium sp. Therefore, the optimized bioprocess can be used for the formulation of liquid microbial inoculants with enhanced shelf stability and could play a pertinent role in integrated nutrient management of forage cowpea for enhanced productivity and quality.
\end{abstract}

Key words: Bioprocess, Bradyrhizobium sp, Burkholderia seminalis, Burkholderia sp., Cowpea, Fodder, Liquid microbial inoculants.

\section{INTRODUCTION}

Plant growth promoting rhizobacteria have the potential for sustainable plant growth promotion in this neoteric era. This journey was started with Rhizobium but now it has broadened its horizon and includes plethora of microorganisms which are not only being exploited for nutrient mobilization or plant growth promotion but also playing a pertinent role in plant protection (PP). Nevertheless, in spite of good going, the actual utilization is nowhere near the potential. Actually, vast variety of the research work was done in the field of strains development, mechanism of action and on exaggerating the science behind their potentiality. Very little work has been done to convert the science into technology (Yadav and Chandra, 2014). To assist high cell numbers and increased survival of microorganisms in soil, preparation of microbial cultures is essential. However, solid carrier based preparations generally suffer from (i) short shelf-life, (ii) poor quality, (iii) high contamination and (iv) low and unpredictable field performances (Vendan and Thangaraju, 2006). To overcome these problems, the liquid carrier based formulations have been introduced (Albareda et al., 2008). Liquid bioinoculants are special liquid formulations containing not only the desired microorganisms and their nutrients, but also the special cell protectants or substances that encourage the longer shelf life and tolerance to adverse conditions (Vora et al.,2008). It has observed that it is possible to make bacteria survive in liquid microbial
${ }^{1}$ Department of Microbiology, Punjab Agricultural University, Ludhiana-141 004, Punjab, India.

${ }^{2}$ Regional Research Station, Punjab Agricultural University, Bathinda-151 001, Punjab, India.

${ }^{3}$ Department of Soil Science, Electron Microscopy and Nanoscience Laboratory, Punjab Agricultural University, Ludhiana-141 001, Punjab, India.

Corresponding Author: Gulab Pandove, Regional Research Station, Punjab Agricultural University, Bathinda-151 001, Punjab, India. Email: gpandove@pau.edu

How to cite this article: Ramya, S., Pandove, G., Kalia, A. (2021). Optimized Bioprocess for the Formulation of Liquid Microbial Inoculants for Forage Cowpea and Insight of Plant-microbe Interaction by SEM. Legume Research. DOI: 10.18805/LR-4741.

Submitted: 20-07-2021 Accepted: 29-09-2021 Online: 03-11-2021

inoculants more than six months with the help of additives/ cell protectants such as methyl cellulose, gum arabic, alginate, polyacrylamide (Bashan et al., 2002). The selection of ideal polymer is based upon several properties like cell adhesion to seed, stabilizer and non-toxicity.

There is a tremendous scope for increasing the yield potential of cowpea by use of microbial inoculants thereby enhancing the nutrient availability and better plant growth (Ramya and Pandove, 2021). The scanning electron 
Optimized Bioprocess for the Formulation of Liquid Microbial Inoculants for Forage Cowpea and Insight of Plant-microbe...

micrographs can furnish brilliant resolution and exact localization of microorganisms in connection to the root structure and can further strengthen plant (host) and plant growth promoting rhizobacteria (PGPRs) interactions. Thereupon, the main objective of the present study was to formulate liquid microbial inoculants with enhanced shelf life and appraisal of liquid microbial inoculants on roots surface of forage cowpea under axenic conditions by scanning electron microscopic (SEM) studies to study plantmicrobe interaction.

\section{MATERIALS AND METHODS} Procurement of test cultures

Three bacterial cultures were evaluated in this study. Burkholderia seminalis an endophytic bacteria was isolated from the root nodules of the vegetable cowpea [Vigna unguiculata (L.) Walp] plants and obtained from Electron Microscopy and Nanoscience Laboratory, Department of Soil Science, PAU, Ludhiana, India. The other bacteria, Burkholderia sp., was isolated from the decomposed paddy straw and obtained from the Department of Microbiology, Punjab Agricultural University, Ludhiana, Punjab, India. The molecular identification of this culture showed similarity with Burkholderia sp. STM1441 based on nucleotide homology and phylogenetic analysis. The reference bacterial culture, Bradyrhizobium sp. (NAIMCC-B-00260) was obtained from National Agriculturally Important Microbial Culture Collection from ICAR-National Bureau of Agriculturally Important Microorganisms (ICAR-NBAIM), Kushmaur, Mau Nath Bhanjan, Uttar Pradesh.

\section{Bioprocess optimization for liquid microbial inoculants formulation and shelf life studies}

\section{Mother culture preparation}

A loopful of pure cultures of Burkholderia seminalis, Burkholderia sp. and Bradyrhizobium sp. was inoculated in $100 \mathrm{ml}$ of autoclaved nutrient broth dispensed in $500 \mathrm{ml}$ flask respectively and incubated at $27 \pm 1^{\circ} \mathrm{C}$ for 48 hours. Further, the growing cells of log phase were used for the further inoculation for each culture respectively.

\section{Optimization of the growth medium for liquid microbial inoculants}

This experiment was conducted to determine the optimum concentration of additives to be added to the basal medium for obtaining the highest population density of the bacteria. The freshly prepared mother culture of $B$. seminalis, Burkholderia sp. and Bradyrhizobium sp. were inoculated @ 1\% to the flask containing $100 \mathrm{ml}$ of autoclaved basal medium with different additives, designated from $T_{1}$ to $T_{17}$ respectively. There were a total of seventeen liquid microbial inoculants formulations for each test cultures. The treatments in detail were as in the Table 1.

Unamended basal medium was used as standard control. All the above inoculated flasks were kept on the shaker at $29+1^{\circ} \mathrm{C}$ for 48 hours and later shifted to stationary
Table 1: Treatment details in basal medium amended with different additives for optimization of growth medium.

\begin{tabular}{|c|c|}
\hline $\mathrm{T}_{1}$ & Basal medium (BM as control) \\
\hline $\mathrm{T}_{2}$ & $B M+P V A 0.5 \%$ \\
\hline $\mathrm{T}_{3}$ & $B M+P V A 1.0 \%$ \\
\hline $\mathrm{T}_{4}$ & $B M+P V A 2.0 \%$ \\
\hline $\mathrm{T}_{5}$ & $B M+P V A 3.0 \%$ \\
\hline $\mathrm{T}_{6}$ & $\mathrm{BM}+$ Trehalose $5 \mathrm{Mm}$ \\
\hline $\mathrm{T}_{7}$ & $\mathrm{BM}+$ Trehalose $10 \mathrm{Mm}$ \\
\hline $\mathrm{T}_{8}$ & $\mathrm{BM}+$ Trehalose $15 \mathrm{Mm}$ \\
\hline$T_{9}$ & $\mathrm{BM}+$ Trehalose $20 \mathrm{Mm}$ \\
\hline $\mathrm{T}_{10}$ & $B M+P E G 0.5 \%$ \\
\hline $\mathrm{T}_{11}$ & $B M+P E G 1 \%$ \\
\hline $\mathrm{T}_{12}$ & $B M+P E G 2 \%$ \\
\hline $\mathrm{T}_{13}$ & $B M+P E G 3 \%$ \\
\hline $\mathrm{T}_{14}$ & BM + Glycerol 1\% \\
\hline $\mathrm{T}_{15}$ & BM + Glycerol 3\% \\
\hline $\mathrm{T}_{16}$ & BM + Glycerol 5\% \\
\hline $\mathrm{T}_{17}$ & BM + Glycerol 7\% \\
\hline
\end{tabular}

phase at room temperature for each culture respectively. One $\mathrm{ml}$ sample from each treatments were drawn on $5^{\text {th }}$, $10^{\text {th }}, 20^{\text {th }}$ and $30^{\text {th }}$ days of storage for total viable counts by dilution pour plate method and plates were incubated at $28 \pm 12^{\circ} \mathrm{C}$ for three days for $B$. seminalis and Burkholderia $\mathrm{sp}$. and for five days for Bradyrhizobium sp.

Liquid microbial inoculants preparation for shelf life studies

For the preparation of liquid microbial inoculants of $B$. seminalis, Burkholderia sp. and Bradyrhizobium sp. The mother culture of each test culture was transferred @ 5\% to each $250 \mathrm{ml}$ flask containing $100 \mathrm{ml}$ of sterilized standardised growth medium respectively and each $250 \mathrm{ml}$ flask containing $100 \mathrm{ml}$ of sterilized basal medium without any additive and inoculated with respective test culture was used as control. The inoculated flasks were now kept on shaker at $28 \pm 1^{\circ} \mathrm{C}$ for 24 hours. They were then transferred into the sterilized $100 \mathrm{ml}$ capacity plastic vials under aseptic conditions (Fig 1).

\section{Preparation of charcoal carrier based microbial inoculants}

Two sets of carrier based inoculants were prepared (Autoclaved and non-autoclaved charcoal) for each test culture. The charcoal carrier was sterilized by tyndalization process in an autoclave at 15 psi pressure and at temperature of $121^{\circ} \mathrm{C}$ for 20 minutes, three times on three succeeding days. The charcoal carrier based formulations were prepared by mixing the broth cultures of respective culture with charcoal powder at 1: 2.5 ratios (Fig 1). Broth cultures were prepared by inoculating a loopful inoculums of pure culture of $B$. seminalis, Burkholderia sp. and Bradyrhizobium sp. in sterilized $200 \mathrm{ml}$ of nutrient broth dispensed in $500 \mathrm{ml}$ flask respectively. The broth culture of respective bacterium was incubated until it reaches maximum cell population count. 
Periodical monitoring of shelf life of liquid microbial inoculants and charcoal carrier based formulations

The plastic vials containing liquid microbial inoculants of B.seminalis, Burkholderia sp. and Bradyrhizobium sp. respectively were stored at room temperature. One $\mathrm{ml}$ of each sample was drawn aseptically at $0^{\text {th }}, 30^{\text {th }}, 60^{\text {th }}, 90^{\text {th }}$, $120^{\text {th }}, 150^{\text {th }}$ and $180^{\text {th }}$ day for total viable count by dilution spread plate method and incubated at $28 \pm 2^{\circ} \mathrm{C}$ for three days for B. seminalis and Burkholderia sp. and five days for Bradyrhizobium sp. Similarly for charcoal carrier based formulations. The total viable count in the charcoal carrier based microbial inoculants was determined by adding 10
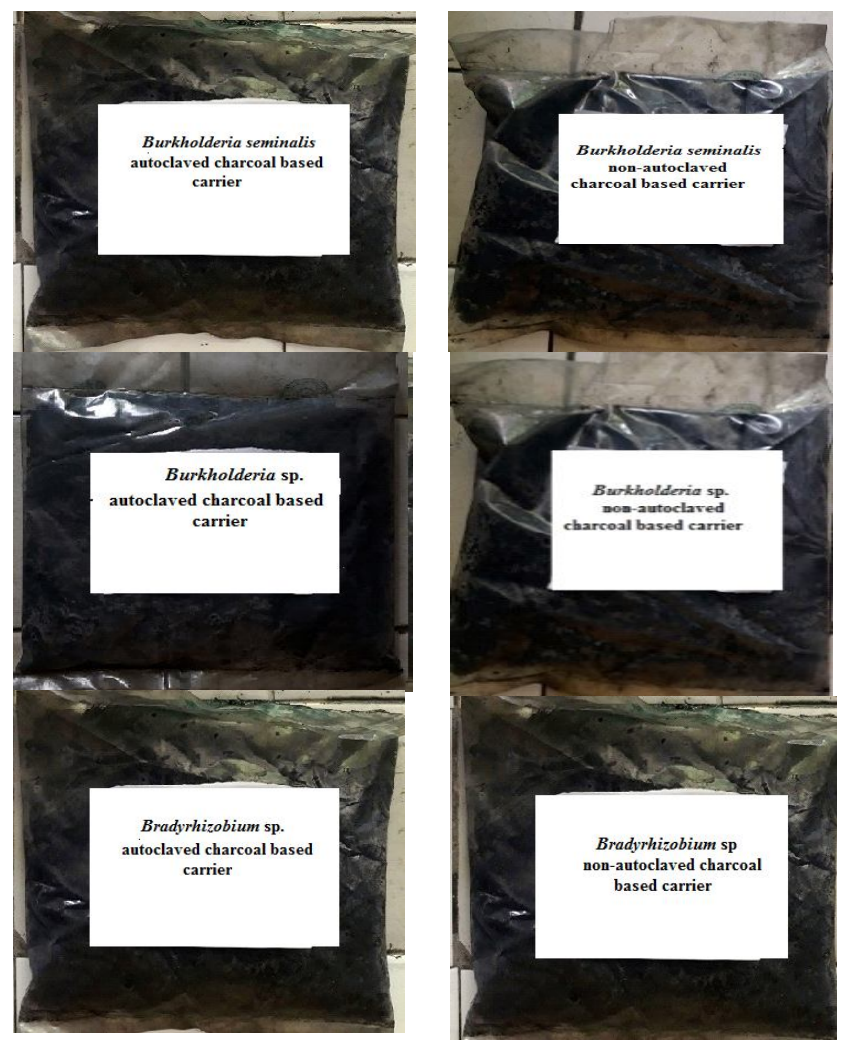

(A)

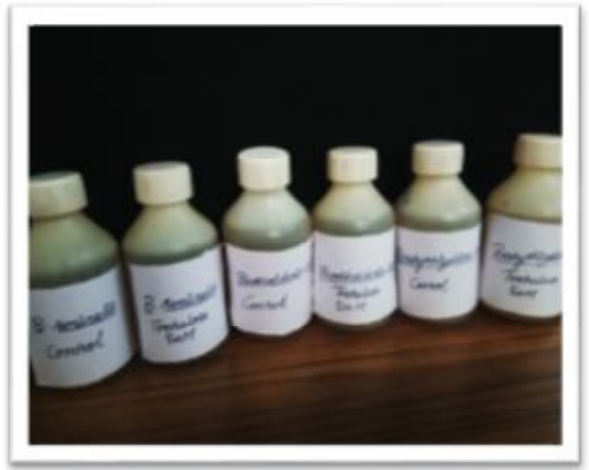

(B)

Fig 1: A) Charcoal based inoculants; B) Liquid microbial inoculants. grams of inoculant to $90 \mathrm{ml}$ of the sterilized distilled water and making a 10-fold dilution series. Then, one $\mathrm{ml}$ aliquots of the appropriate dilutions were spread plated on nutrient agar medium aseptically at $0^{\text {th }}, 30^{\text {th }}, 60^{\text {th }}, 90^{\text {th }}, 120^{\text {th }}, 150^{\text {th }}$ and $180^{\text {th }}$ day. Colonies were counted after incubation $\left(28^{\circ} \mathrm{C}\right)$ of three days for B.seminalis and Burkholderia sp. and five days for Bradyrhizobium sp.

Insight of liquid microbial inoculant colonization of roots surface of forage cowpea under gnotobiotic condition by scanning electron microscopic studies

The roots of forage cowpea were examined for colonization by liquid microbial inoculants of $B$. seminalis, Burkholderia sp. and Bradyrhizobium sp. respectively by Scanning electron microscopic studies.

The cowpea seeds of variety CL-367 were first surfacesterilized with $2.5 \%$ sodium hypochlorite solution for five minutes, followed by $70 \%$ ethanol for five minutes and then rinsed continuously with sterilized water for eight times. Sterilized seeds were then treated with liquid microbial inoculants of B.seminalis, Burkholderia sp. and Bradyrhizobium sp. respectively and allowed to sit for 30$45 \mathrm{~min}$ in the sterilized petriplates. The treated seeds were placed aseptically in the test tubes containing $0.85 \%$ agar gel $(0.85 \mathrm{~g}$ in $100 \mathrm{ml})$ using sterilized forceps respectively for each treatments i.e B.seminalis, Burkholderia sp. and Bradyrhizobium sp., In one set of the tubes sterilized untreated seeds were placed and it was used as control. Further for each treatment, a total of 5 test tubes were maintained. The tubes were then incubated at room temperature under light for 2 weeks. To further strengthen the impact of liquid microbial inoculants, periodical observation of root length was taken at 5 days interval.

\section{Scanning electron microscopy (SEM)}

Fresh fine root samples were fixed in 2.5-3.0\% gluteraldehyde for 4 hours and washed in $0.1 \mathrm{M}$ sodium cacodylate buffer ( 3 changes) for one hour. Then, the roots were dehydrated by dipping in the increasing concentrations of acetone in water and finally washed in $100 \%$ acetone. The samples were dried using the tetra-methyl silane (TMS) method in which the specimens were immersed in TMS for 5-10 min for two changes at $4^{\circ} \mathrm{C}$ followed by drying at room temperature $\left(25-26^{\circ} \mathrm{C}\right)$. The root samples were mounted on brass or aluminium stubs and coated using silver or gold $(35 \mathrm{~nm})$ thick before being examined and digested under SEM.

\section{RESULTS AND DISCUSSION}

Bioprocess optimization for the formulation of liquid microbial inoculants

In the present study to enhance the shelf life of liquid formulation of microbial inoculants, additives like Poly vinyl alcohol, Trehalose, Poly ethylene glycol and Glycerol were exploited to standardise liquid formulation of microbial inoculants. The viability of all the three test cultures were 
evaluated for one month in the medium amended with different concentration of polyvinyl alcohol (PVA) $(0.5 \%, 1 \%$, $2 \%$ and $3 \%$ ), trehalose (5 mM, $10 \mathrm{mM}, 15 \mathrm{mM}$ and $20 \mathrm{mM})$, polyethylene glycol (PEG) $(0.5 \%, 1 \%, 2 \%$ and $3 \%)$ and glycerol ( $1 \%, 3 \%, 5 \%$ and $7 \%)$.

For $B$. seminalis, at $5^{\text {th }}$ day and $30^{\text {th }}$ day maximum growth and survival was observed in the basal medium amended with $5 \mathrm{mM}$ trehalose (Fig 3). In the entire amended basal medium, $B$. seminalis showed superior growth over the control (without additives). Similarly, Burkholderia sp. and Bradyrhizobium sp. showed maximum count i.e 10.32 $\log _{10}$ no of viable cells $/ \mathrm{ml}$ and $10.41 \log _{10}$ no of viable cells/ $\mathrm{ml}$ respectively in basal medium amended with $5 \mathrm{mM}$ trehalose at $30^{\text {th }}$ day at room temperature (Fig 4 and 5). This might be attributed to the capability of trehalose in enhancing cell tolerance to desiccation, osmotic pressure and temperature stress (Streeter, 2003) and stabilizing both enzymes and cell membranes (Fillinger et al., 2001).

\section{Periodical monitoring of shelf life of liquid microbial inoculant of B.seminalis at room temperature}

The data pertaining to survivability of $B$. seminalis in liquid microbial inoculant without trehalose $5 \mathrm{mM}\left(B \mathrm{BT}_{1}\right)$, liquid inoculant with trehalose $5 \mathrm{mM}\left(\mathrm{BT}_{2}\right)$, autoclaved charcoal carrier based inoculant $\left(\mathrm{BST}_{3}\right.$ ) and non-autoclaved charcoal carrier based inoculant $\left(\mathrm{BST}_{4}\right)$ at room temperature has been presented in Table 2. Highest viable count of $B$. seminalis was observed in $\mathrm{BST}_{2}$ followed by $\mathrm{BST}_{3}$ and least vial count was observed in $\mathrm{BST}_{1}$. However, microbial inoculants prepared using non-autoclaved charcoal carrier $\left(\mathrm{BST}_{4}\right.$ ) showed contamination throughout the study.
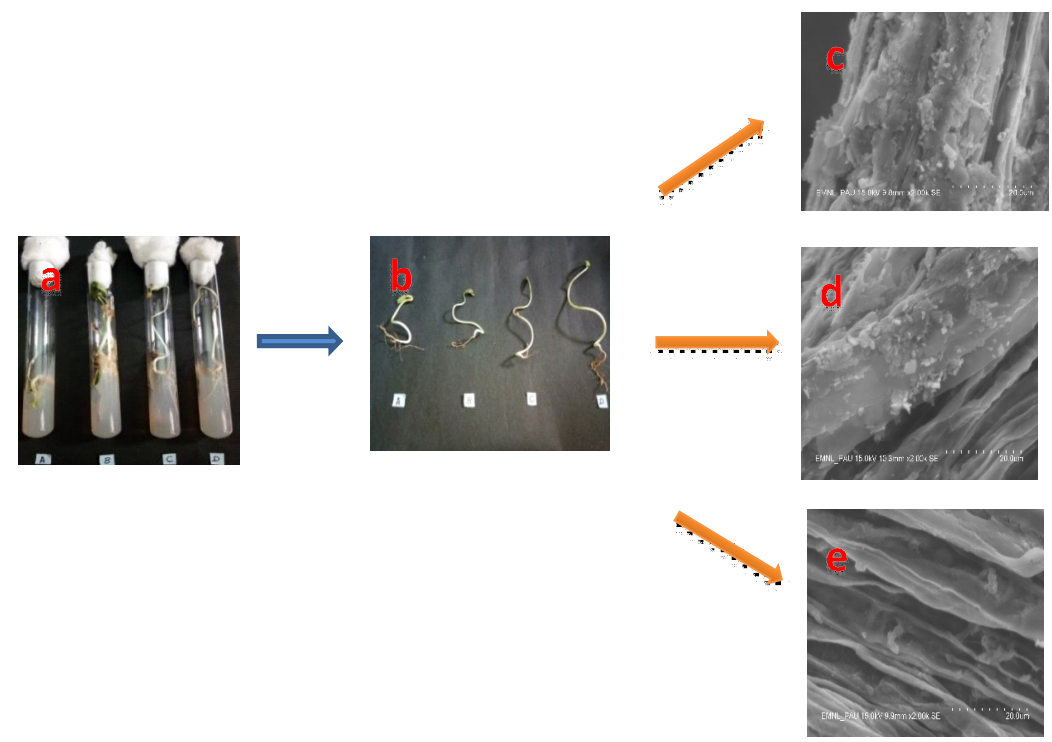

Fig 2: Scanning electron microscopic image of the surface of the cowpea roots.

(a) Agar gel $(0.85 \% \mathrm{w} / \mathrm{v})$ assembly (b) images of plants, seed inoculated with three bacterial cultures and control (A: control, B: Bradyrhizobium, C: Burkholderia sp. and D: Burkholderia seminalis) c), d), e), SEM micrographs of root surface.

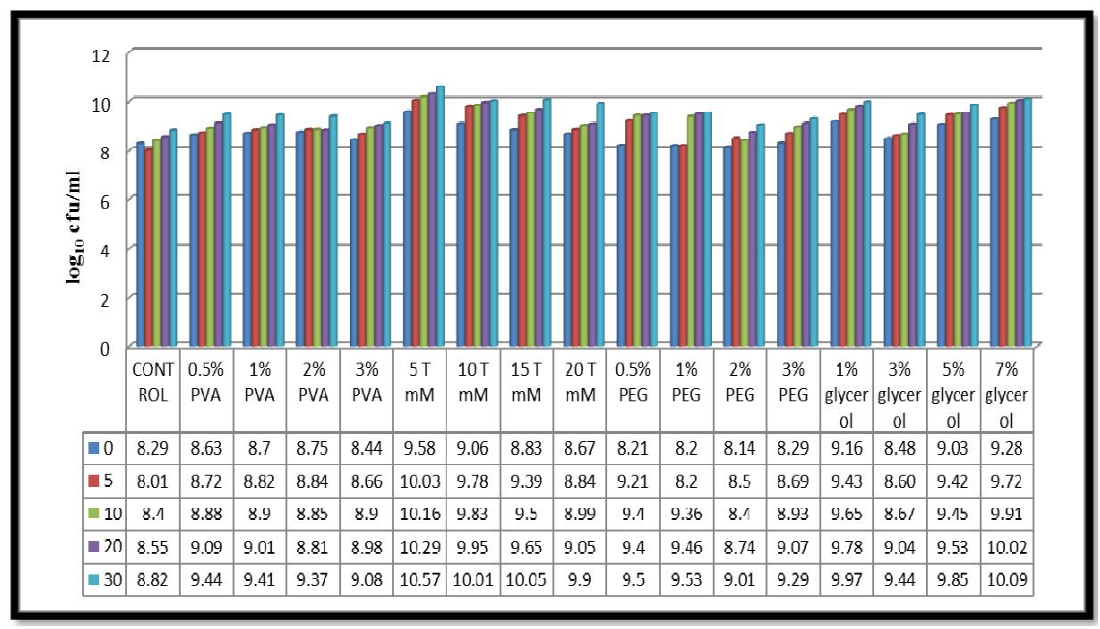

Fig 3: Survival of Burkholderia seminalis in basal medium amended with different additives. 
Initially liquid microbial inoculant with trehalose $5 \mathrm{mM}$ $\left(\mathrm{BST}_{2}\right.$ ) showed $10.49 \log _{10}$ no. of viable cells which increased to $10.88 \log _{10}$ no. of cells at $90^{\text {th }}$ day (with increase of 3.71 per cent) and further decreased to 9.21 no. of $\log _{10}$ cells at $180^{\text {th }}$ day (with decrease of 12.2 per cent) at room temperature. In autocalved charcoal based carrier, initial count was $10.31 \log _{10}$ no. of cells which reduced to 8.20 $\log _{10}$ no. of cells at $180^{\text {th }}$ day $(20.46 \%$ decrease $)$ where as in liquid inoculant without trehalose $\left(B \mathrm{BT}_{1}\right)$ initial count of $10.16 \log _{10}$ no. of viable cells were observed which decreased to $4.23 \log _{10}$ no. of cells at $180^{\text {th }}$ day (decrease of $58.36 \%$ ) at room temperature. Microbial inoculants prepared using non-autoclaved charcoal carrier showed contaminated throughout the study period.

The results are supported by the findings of Soni et al. (2017) who reported that trehalose as additive maintained the viable counts of Burkholderia cepia (10.933- 6.77 log $\mathrm{CFU} / \mathrm{ml}$ ) throughout the year at room temperature.

\section{Periodical monitoring of shelf life of liquid microbial} inoculants of Burkholderia sp. at room temperature

The data pertaining to survivability of Burkholderia sp. in liquid microbial inoculant without trehalose $5 \mathrm{mM}\left(\mathrm{BT}_{1}\right)$, liquid inoculant with trehalose $5 \mathrm{mM}\left(\mathrm{BT}_{2}\right)$, autoclaved charcoal carrier based inoculant $\left(\mathrm{BT}_{3}\right)$ and non-autoclaved charcoal carrier based inoculant $\left(\mathrm{BT}_{4}\right)$ at room temperature has been presented in Table 2. Highest viable count of Burkholderia sp. was observed in $\mathrm{BT}_{2}$ followed by $\mathrm{BT}_{3}$ and least vial count was observed in $\mathrm{BT}_{1}$. Microbial inoculants prepared using non-autoclaved charcoal carrier $\left(\mathrm{BT}_{4}\right)$ showed contamination throughout the study.

Initially $10.62 \log _{10}$ no. of viable cells were observed which reduced to $9.28 \log _{10}$ no. of cells at $180^{\text {th }}$ day (with the decrease of 12.61 per cent) in liquid microbial inoculant amended with trehalose $5 \mathrm{mM}\left(\mathrm{BT}_{2}\right)$. In charcoal based carrier, initial count was $10.16 \log _{10}$ no. of cells which reduced to $8.24 \log _{10}$ no. of cells at $180^{\text {th }}$ day $(18.89 \%$ decrease) where as in liquid microbial inoculant without trehalose $\left(\mathrm{BT}_{1}\right)$ initial count was $10.30 \log _{10}$ no. of cells which further decreased to $3.68 \log _{10}$ no. of cells at $180^{\text {th }}$ day at room temperature $(64.27 \%$ decrease).

These results were well corroborated with the results that indicate the growth of bacteria with trehalose in the medium resulted in $294 \%$ increase in survival (Streeter 2003).

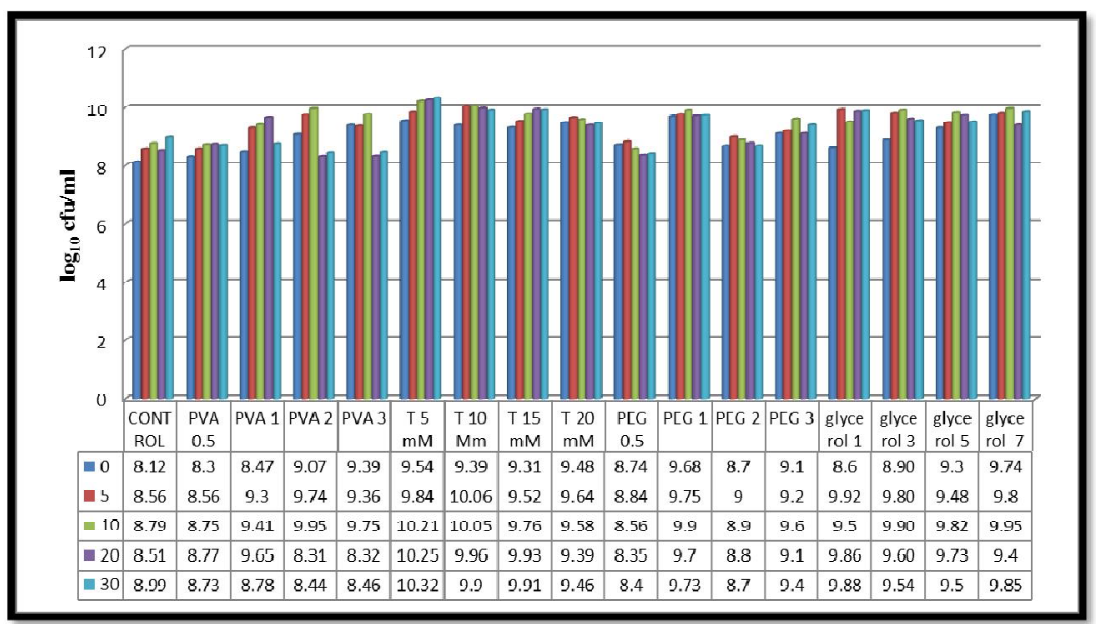

Fig 4: Survival of Burkholderia sp. in basal medium amended with different additives.

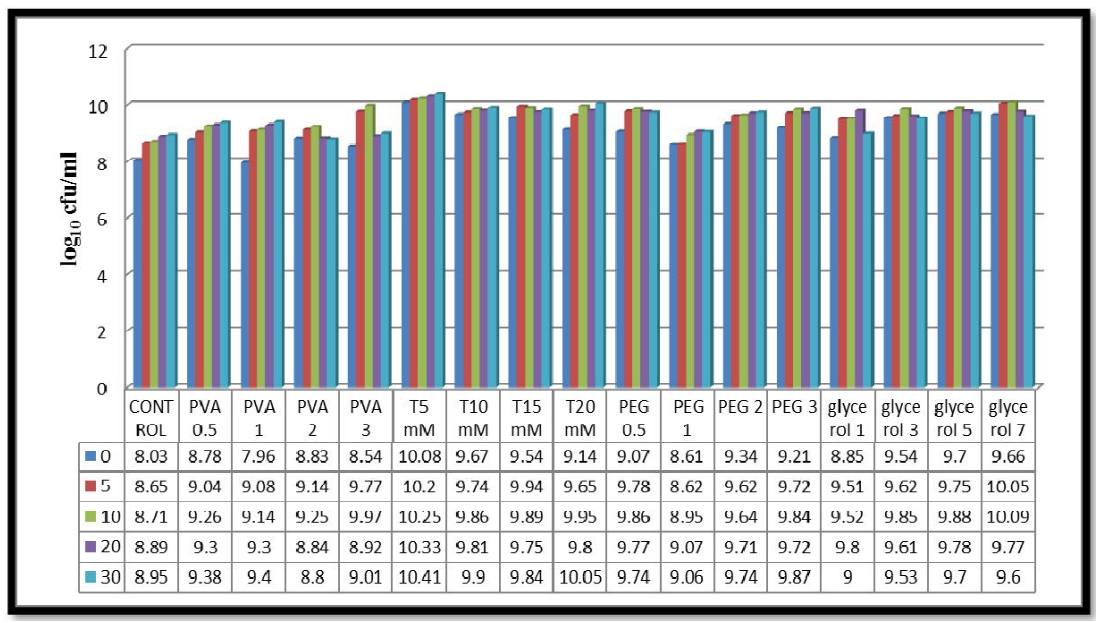

Fig 5: Survival of Bradyrhizobium sp. in basal medium amended with different additives. 
Optimized Bioprocess for the Formulation of Liquid Microbial Inoculants for Forage Cowpea and Insight of Plant-microbe...

Periodical monitoring of shelf life of liquid microbial inoculants of Bradyrhizobium sp. at room temperature

The perusal of the data in Table 2 indicated that at room temperature, the liquid microbial inoculant of Bradyrhizobium sp. amended with trehalose $5 \mathrm{mM}\left(\mathrm{BRT}_{2}\right)$ supported better viability as compared to liquid broth without trehalose $5 \mathrm{mM}$ $\left(B R T_{1}\right)$, charcoal based carrier $\left(\mathrm{BRT}_{3}\right)$ and non-autoclaved charcoal based carrier $\left(\mathrm{BRT}_{4}\right)$. Initially $10.23 \log _{10}$ no. of viable cells were observed in liquid microbial inoculant without trehalose $5 \mathrm{mM}\left(\mathrm{BRT}_{1}\right)$ which decreased to $4.11 \log _{10}$ no. of cells at $180^{\text {th }}$ day at room temperature (with decrease of 59.82 per cent). This may be due the stationary phase achievement and desiccation of cells. The liquid inoculant amended with trehalose $5 \mathrm{mM}\left(\mathrm{BRT}_{2}\right)$ initially showed 10.29 $\log _{10}$ no. of viable cells which increased to $10.65 \log _{10}$ no. of cells at $90^{\text {th }}$ day which further decreased to 9.39 no. of $\log _{10}$ cells at $180^{\text {th }}$ day (with decrease of 8.75 per cent) followed by autoclaved charcoal based carrier microbial inoculant of Bradyrhizobium sp. $\left(\mathrm{BRT}_{3}\right)$ with $10.18 \log _{10}$ no. of cells initially which decreased to $8.16 \log _{10}$ no. of cells (with decrease of 19.84 per cent) at $180^{\text {th }}$ day. Further, microbial inoculant prepared using non-autoclaved charcoal showed contamination throughout the study period.

Overall our findings in the present study were in line with Streeter, (2003) who proved feasible to add trehalose to the culture medium containing $B$. japonicum where trehalose was found accumulated in the cells during growth and further added that trehalose concentration in cells could be a useful predictor of survival during desiccation.
Hence, technology for the preparation of liquid microbial inoculants using trehalose as additive would be an attractive alternative to prepare microbial inoculants with enhanced shelf life.

Insight of root colonization of forage cowpea by liquid microbial inoculants under gnotobiotic conditions by scanning electron microscopic studies

In the present study, surface sterilized forage cowpea seeds were treated with liquid microbial inoculants of Burkholderia seminalis, Burkholderia sp. and Bradyrhizobium sp. and placed in agar gel assembly, incubated at $25 \pm 2^{\circ} \mathrm{C}$ for 15 days (Fig 2). After two weeks of incubation, the root surface of the germinated cowpea seedlings from each treatment was observed under scanning electron microscope following processing (Fig 2c, 2d and 2e).

Micrographs of SEM from root explant of seedling at $15^{\text {th }}$ day after inoculation with Burkholderia seminalis, Burkholderia sp. and Bradyrhizobium sp. showed root surface colonization of primary and lateral roots, root hair zone, lateral root junction, in root tissue crevices, elongation and discrimination zones of the root tips (Fig 6). Burkholderia seminalis colonized the root surface of cowpea seedlings non-uniformly occurring as aggregates or groups (arrows in Fig 6a). Root surfaces from Burkholderia seminalis inoculated seedlings were associated with fibrillar material, which resulted in the formation of "microcolonies" (Fig 6d). The nature of this fibrillar materials might be anticipated as secretion and deposition of the extracellular polymeric substances comprised of primarily polysaccharides and

Table 2: Survival of Burkholderia seminalis, Burkholderia sp and Bradyrhizobium sp. in microbial inoculants at room temperature.

\begin{tabular}{|c|c|c|c|c|c|c|c|c|}
\hline \multirow{3}{*}{ Treatments } & \multicolumn{8}{|c|}{ Survival of cells upto 6 months (log no. of cells $/ \mathrm{ml}$ ) } \\
\hline & \multicolumn{8}{|c|}{ Days } \\
\hline & 0 & 30 & 60 & 90 & 120 & 150 & 180 & C.D \\
\hline BST1 & 10.16 & 10.34 & 8.69 & 7.39 & 6.93 & 5.17 & 4.23 & 2.15 \\
\hline BST2 & 10.49 & 10.66 & 10.76 & 10.88 & 10.27 & 9.36 & 9.21 & NS \\
\hline BST3 & 10.31 & 10.33 & 10.38 & 10.62 & 9.47 & 8.62 & 8.2 & NS \\
\hline BST4 & $9.57^{*}$ & $9.42^{*}$ & $9.44^{*}$ & $8.68^{*}$ & $8.52^{*}$ & $8.28^{*}$ & $8.11^{*}$ & NS \\
\hline BT1 & 10.3 & 10.44 & 8.51 & 7.56 & 6.17 & 6.15 & 3.68 & 1.85 \\
\hline BT2 & 10.62 & 10.63 & 10.75 & 10.84 & 9.95 & 9.51 & 9.28 & NS \\
\hline BT3 & 10.16 & 10.42 & 10.49 & 10.46 & 8.41 & 8.34 & 8.24 & NS \\
\hline BT4 & $10.12^{*}$ & $9.93^{*}$ & $9.62^{*}$ & $9.10^{*}$ & $8.57^{*}$ & $7.59^{*}$ & $7.36^{*}$ & NS \\
\hline BRT1 & 10.23 & 9.95 & 7.5 & 7.43 & 5.59 & 4.53 & 4.11 & 1.73 \\
\hline BRT2 & 10.29 & 10.63 & 10.78 & 10.65 & 9.66 & 9.44 & 9.39 & NS \\
\hline BRT3 & 10.18 & 10.32 & 10.34 & 10.59 & 9.32 & 8.4 & 8.16 & 1.47 \\
\hline BRT4 & $9.63^{*}$ & $9.37^{*}$ & $9.24^{*}$ & $8.21^{*}$ & $8.36^{*}$ & $7.52^{*}$ & $7.23^{*}$ & 1.6 \\
\hline
\end{tabular}

${ }^{*}$ Contamination.

Note: $\mathrm{BST}_{1}$ : Liquid microbial inoculant of Burkholderia seminalis without $5 \mathrm{mM}$ Trehalose; $\mathrm{BST}_{2}$ : Liquid microbial inoculant of Burkholderia seminalis with $5 \mathrm{mM}$ Trehalose; $\mathrm{BST}_{3}$ : Autoclaved charcoal based carrier inoculant of Burkholderia seminalis; $\mathrm{BST}_{4}$ : Non-autoclaved charcoal based carrier inoculant of Burkholderia seminalis; $\mathrm{BT}_{1}$ : Liquid microbial inoculant of Burkholderia sp. without 5 mM Trehalose; $\mathrm{BT}_{2}$ : Liquid microbial inoculant of Burkholderia sp. with $5 \mathrm{mM}$ Trehalose; $\mathrm{BT}_{3}$ : Autoclaved charcoal based carrier inoculant of Burkholderia $\mathrm{sp} ; \mathrm{BT}_{4}$ : Non-autoclaved charcoal based carrier inoculant of Burkholderia sp; BRT 1 : Liquid microbial inoculant of Bradyrhizobium sp. without $5 \mathrm{mM}$ Trehalose; $\mathrm{BRT}_{2}$ : Liquid microbial inoculant of Bradyrhizobium sp. with $5 \mathrm{mM}$ Trehalose; BRT ${ }_{3}$ : Autoclaved charcoal based carrier inoculant of Bradyrhizobium sp; $\mathrm{BRT}_{4}$ : Non-autoclaved charcoal based carrier inoculant of Bradyrhizobium sp. 


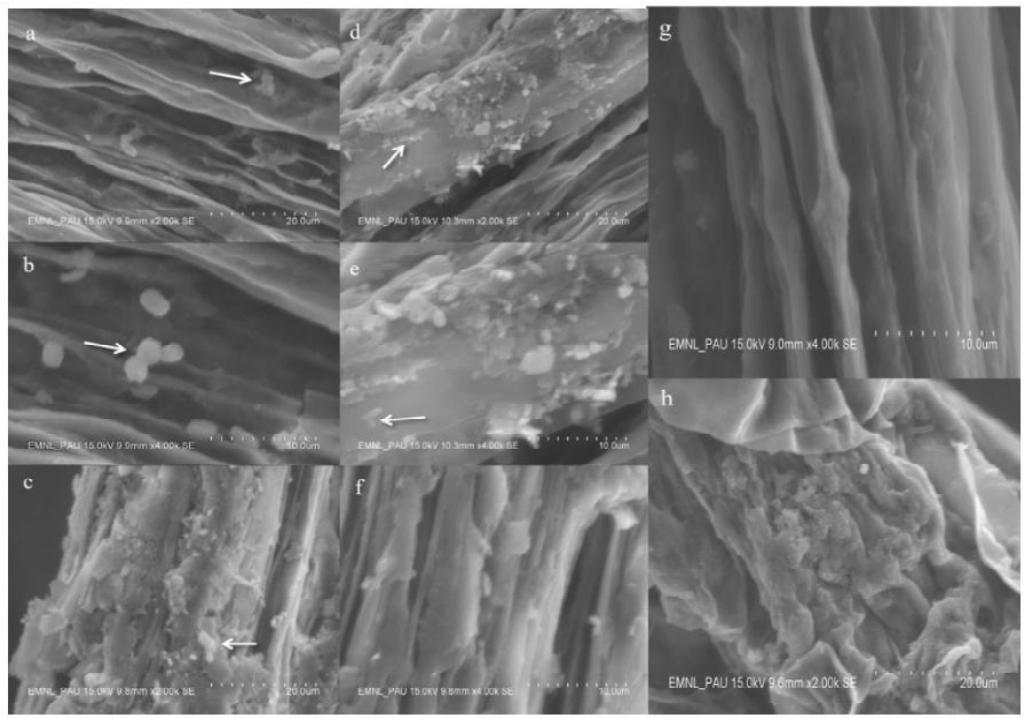

Fig 6: Scanning electron micrographs depict root colonization by Burkholderia seminalis, Burkholderia sp. and Bradyrhizobium sp. in 15 days old seedling of forage cowpea grown under gnotobiotic conditions.

a) Cells of Burkholderia seminalis in aggregates or groups on the root surface of forage cowpea (2000X magnification).

b) Colonization of Burkholderia sp. on the root surface of forage cowpea seedlings in triplets (indicated by arrows, 4000X magnification).

c) Cells of Bradyrhizobium sp. on the root surface of forage cowpea seedlings occurring as single cells (2000X magnification).

d) Small cell aggregates or microcolonies (indicated by arrows) of Burkholderia seminalis on the root surface (2000X magnification).

e) Burkholderia sp. and f) Bradyrhizobium sp. inoculated root surface of forage cowpea seedling (4000X magnification).

g) Showing no bacteria on the root surface of uninoculated forage cowpea seedling at $4000 \mathrm{X}$ magnification and $\mathrm{h}$ ) at $2000 \mathrm{X}$ magnification.

glycoproteins. Haas and Defago (2005) have also demonstrated that endophytes secrete secondary metabolites that allow them to colonize internal host tissue. Further, chronologically endophytes can be detected first on root surfaces followed by their presence in the internal root tissues. Further, colonization of root surfaces of forage cowpea seedlings by Burkholderia sp. using electron microscopy has provided topographical and morphological images of the colonization features of rhizobacteria. Scanning electron microscopy showed that Burkholderia sp. randomly colonized the root surface of cowpea seedlings as aggregates or as doublets and triplet cells (Fig 6b and 6e). These micrographs also revealed that Burkholderia sp. cells were densely distributed throughout the surface of the roots of the cowpea seedlings. Further, plant roots release plethora of root exudates (sugars, amino acids, organic acids and phenolic fractions) and result in significant stimulation of the microbial growth and activity.

Similarly, roots from 15 days old seedling inoculated with Bradyrhizobium sp. observed through SEM showed that the Bradyrhizobium sp. were able to colonize the surface of the roots (Fig 6c and 6f). SEM micrographs showed less number of rod shaped bacterial cells of Bradyrhizobium sp. on the root surface. The production of extracellular polysaccharide substance (EPS) or cell aggregation might have favoured the colonization process.

Root seedlings free of inoculant bacteria typically revealed no colonization of epidermal root surface (Fig $6 \mathrm{~g}$ and $6 \mathrm{~h}$ ). Furthermore, the microflora associated with the roots affects plant growth and health. The ability to colonize plant roots can lead to increased biological nitrogen fixing activity for the plant). This study demonstrated that plant growth can be augmented by inoculation with liquid microbial inoculants of Burkholderia seminalis, Burkholderia sp. and Bradyrhizobium sp. On the $15^{\text {th }}$ day, maximum root length of forage cowpea was showed by Burkholderia seminalis $(10.2 \mathrm{~cm})$ followed by Burkholderia sp. $(8.3 \mathrm{~cm})$ and Bradyrhizobium sp. $(7.6 \mathrm{~cm})$ and uninoculated control (6.8). This might also be due to the production of phytohormones by the inoculants.

There upon, SEM has provided a comprehensive understanding of microbial inoculant colonization on the root surface of plants.

\section{CONCLUSION}

Liquid microbial inoculants (LMI) formulated in the present study is a viable and stable technology with improved shelf stability. Further, the scanning electron micrographs revealed the insight of plant-microbe interaction. Therefore, LMI of forage cowpea can play pertinent role in improving the yield and quality of forage cowpea in the neoteric era of bio evolution.

\section{REFERENCES}

Albareda, M., Rodríguez-Navarro, D.N., Camacho, M. and Temprano, F.J. ( 2008). Alternatives to peat as a carrier for rhizobia inoculants: Solid and liquid formulations. Soil Biol. Biochem. 40: 2771-79. 
Bashan, Y., Hernandez, J., Leyva, A., Luis, Bacilio, Macario. (2002). Alginate microbeads as inoculant carrier for plant growth-promoting bacteria. Biol. Fert. Soils. 35: 359-68.

Fillinger, Chaveroche, M.K., Dijck, P.V., Vries, R.D., Ruijter, G., Thevelein, J. and Christophe d'Enfert. (2001). Trehalose is required for the acquisition of tolerance to a variety of stresses in the filamentous fungus Aspergillus nidulans. Microbiol. 147: 1851-62.

Haas, D. and Defago, G. (2005). Biological control of soil-borne pathogens by fluorescent pseudomonads. Nat. Rev. Microbiol. 3: 307-19.

Ramya, S. and Pandove, G. (2021). Integrated nutrient management in cowpea with the application of microbial inoculants. Legume Res. 44: 243-251.

Soni, R.K., Kanwar, A. and Singh, S. (2017). Efficacy of liquid formulation of versatile rhizobacteria isolated from soils of the North-Western Himalayas on Solanum lycopersicum. IJTK. 16 (4).
Streeter, J.G. (2003). Effect of trehalose on survival of Bradyrhizobium japonicum during desiccation. J. Appl. Microbial. 95(3): 484-91.

Vendan, R.T. and Thangaraju, M. (2006). Development and standardization of liquid formulation for Azospirillum bioinoculant. Indian J. of Microbial. 46: 379-87.

Vora, M.S., Shelat, H.N. and Vyas, R.V. (2008). Liquid Biofertilizers: A New Vistas. In: Handbook of Biofertilizers and Microbial Pesticides, Satish Serial Publishing House, New Delhi, pp 87-90.

Yadav, A.K. and Chandra, K. (2014). Mass Production and Quality Control of Microbial Inoculants. Proc. Indian Natn. Sci. Acad. 2: 483-489. 